\title{
Density-dependent Growth in the Northwest Atlantic Stock of Atlantic Mackerel (Scomber scombrus)
}

\author{
W. J. Overholtz \\ National Marine Fisheries Service, Northeast Fisheries Center \\ Woods Hole Laboratory, Woods Hole, Massachusetts 02543, USA
}

\begin{abstract}
Density-dependent growth relationships in the Northwest Atlantic stock of Atlantic mackerel (Scomber scombrus) were investigated with regression and non-parametric statistical procedures. Mean weight at ages 1-3 for research survey caught and ages 2-4 for commercially caught fish were found to be significantly and negatively correlated with stock density. Weight-at-age of fish from the 1978-82, and 1984 cohorts were significantly different at ages 1,2 and 3 . The 1982 cohort was found to be one of the slowest growing on record; it is also one of the largest recruiting year-classes that has been observed. Results suggested that a two stage growth model that accounts for different distribution of juvenile and adult fish may be appropriate for this stock. Early growth may be related to year-class size, whereas stock size may be more influential after juvenile fish join the adult stock further offshore.
\end{abstract}

\section{Introduction}

Atlantic mackerel (Scomber scombrus) have historically been important to the USA domestic fishery, with cumulative landings since the early-1800s totalling over 7 million metric tons (Sette and Needler, 1934; Hoy and Clark, MS 1967; Anderson and Paciorkowski, 1980). A large domestic industry declined in the 1940s due mainly to decreased demand for Atlantic mackerel, which have oily, dark-coloured flesh (Jensen, MS 1967). After a 25-year lull, a resurgence of the fishery occurred in the 1970s when distant water fleets from eastern Europe and the USSR landed an estimated average of 310,000 tons annually from 1970 to 1976 (Anderson and Paciorkowski, 1980). Reported catches increased from 10,000 tons in 1960 to a peak of 430,000 tons in 1973 and then declined to 78,000 tons in 1978. The Magnuson Act of 1976 established control of the resource under the auspices of the Mid-Atlantic Fishery Management Council. Under the guidance of the Council, landings from 1983 to 1986 averaged only 52,000 tons, while a succession of moderate to good year-classes from 1981 to 1985 promoted a rapid increase in biomass to levels observed in the early 1970 s. Along with the fluctuations in biomass that have accompanied the decline in the 1970 s and recovery in the 1980s have come large changes in size-at-age (Overholtz et al., MS 1988).

The indeterminate and plastic nature of fish growth has long been established as a result of laboratory and field studies that have confirmed the relationship between growth and important factors such as population density, food ration, competition, and environmental conditions (Ivlev, 1961; Borgenson, 1966; Tyler and
Dunn, 1976; Moreau, 1987). The important connection between intraspecific population density and growth rate was first established centuries ago in fresh water fishes by fish culturists, but has only been documented experimentally in more contemporary times (Backiel and LeCren, 1967). Numerous studies have recorded density-dependent growth in fishes (Weatherly and Gill, 1987), but fewer have presented valid statistical arguments for an inverse relationship between density and growth (Ross and Almeida, 1986). Several studies have suggested that density-dependent growth in Northwest Atlantic marine fishes may be a common occurrence (Clark et al., 1982; Templeman and Bishop, 1979; Ross and Almeida, 1986).

The objective of this study was to investigate the effect of density on growth in the Atlantic mackerel stock found along the coast of eastern Canada and the USA (Fig. 1). Several independent sources of information suggest that recent patterns of growth in this stock have fluctuated dramatically (Fig. 2). The relationship between mean weight-at-age and stock size was explored with data from commercial fishery and research survey sources. In addition, the differences in mean size between recent year-classes was quantified and tested statistically.

\section{Materials and Methods}

Data were obtained from research cruises and commercial catch sources. Atlantic mackerel from spring groundfish surveys, conducted by the Northeast Fisheries Center from Cape Hatteras, North Carolina to Nova Scotia during March-May, 1976-85, were col- 


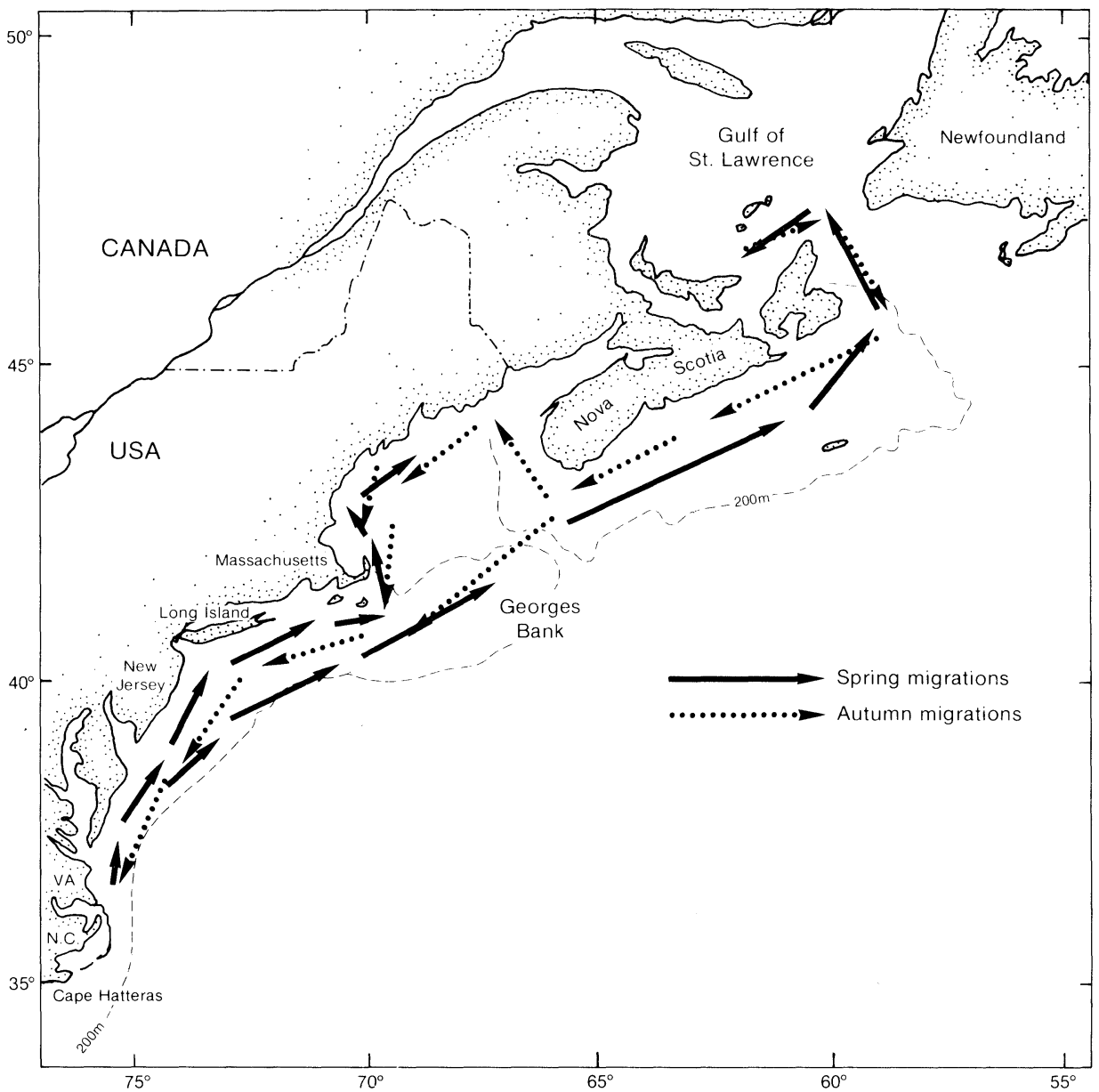

Fig. 1. Seasonal changes in distribution for the Northwest Atlantic stock of Atlantic mackerel. The winterspring fishery occurs off the eastern USA from Massachusetts to Virginia. The northern component spawns in the Gulf of St. Lawrence in June whereas the southern component spawns off New Jersey and Long Island in May.

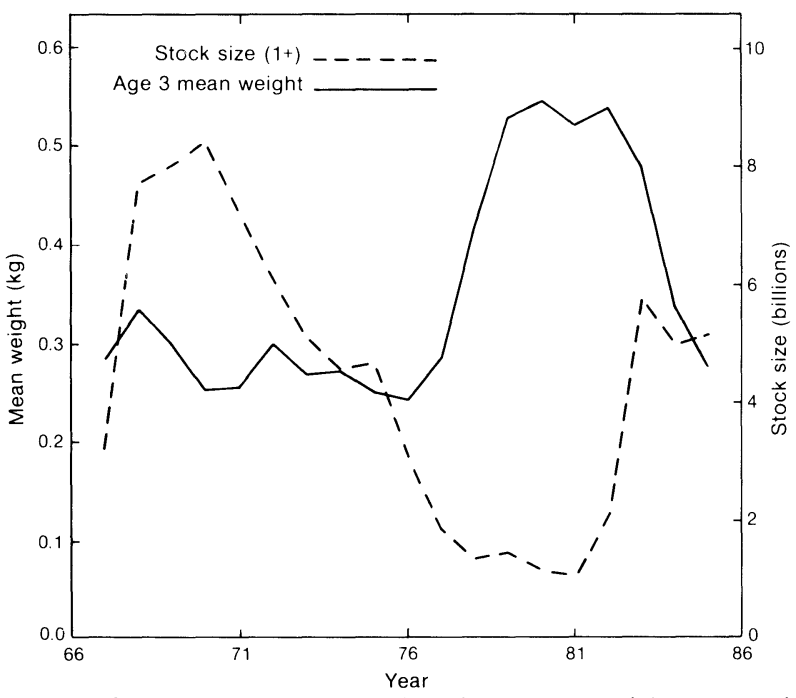

Fig. 2. Stock size and mean weight from commercial catches of Atlantic mackerel for 1967-85. lected and measured fork length (FL) to the nearest $\mathrm{cm}$ while at sea. The design of the research surveys has been described in detail in other studies (Grosslein, 1969; Azarovitz, 1981). These surveys which were conducted using a stratified-random design with standardized gear and procedures, provided an excellent opportunity for obtaining biological information on age composition, reproductive biology, distribution and growth of Atlantic mackerel.

For statistical comparisons of individual yearclasses, commercial samples from two sources, namely, Polish commercial fishery operations and USA domestic landings from January to April 1979-86 were used. This time period precedes spawning and due to limited feeding little growth occurs. Hence, the growth data obtained from this time period were useful for statistical comparisons and correlation analyses. Random samples of fish were collected for age determinations in $1-\mathrm{cm}$ length groups and frozen for later 
analysis. Fish were measured ( $F L$ ) to the nearest $\mathrm{cm}$ and weighed (to the nearest $\mathrm{g}$ ) in the laboratory before otoliths were removed.

For the stock density and growth comparisons, annual age composition data was applied to length frequency data from research surveys for 1976-85 and thousands of FL measurements taken annually from commercial fishing sources for 1967-85. Mean lengthsat-age were obtained by calculating a weighted mean for each age group. Mean weight-at-age for both commercial landings and research survey catches were calculated from separate length-weight equations, developed from previous sampling.

Scatter plots of survey data, ages 1-14, mean weights versus stock size (total numbers) were examined for evidence of a negative relationship between age group and stock density (1+ numbers). The scatter diagrams for ages 1-5 indicated that mean weight possibly declined with increasing stock size, consistent with previous unpublished studies that suggested a density-dependent relationship for young mackerel. To quantify the relationship between survey mean weights (1976-85) of age 1-5 fish and stock size (1+ numbers), regression analysis was performed on each age group. Regressions of commercial mean weight at age 1-9 versus stock size (1+ numbers) were completed for 1967-85 to examine the relationship further.

Regressions were used to determine if there was a relationship between year-class size and mean weightat-age (individually weighed fish, 1979-86) of a yearclass; for ages 1 and 2 . There were not enough age-3 data available to attempt an analysis on this age group.

Individual fish weights obtained from fish weighed in the laboratory from Polish and USA commercial trawlers for the 1978-82, and the 1984 year-classes at age 1, 2 and 3 were examined and tested with nonparametric analysis of variance (Kruskal-Wallis tests) to determine if there were differences in weight between year-classes. Non-parametric measures were used because they do not require assumptions about the underlying distributions of the sample populations, and they are easily applied to data (Hollander and Wolfe, 1973). Because sample sizes were different $(n=$ 30 to 100), the data were randomized to provide a set of equal sample sizes for each year-class. This allowed an easier application of the methods to the data and the sample sizes after subsampling were still all large (i.e. $\geqslant 30$ ) (Hollander and Wolfe, 1973). The sample with the lowest number of observations was chosen as the minimum sample size and the subsamples were picked randomly to equal this minimum number. Sample sizes obtained were 36,30 and 50 for the age 1, 2 and 3 analyses respectively.

Kruskal-Wallis tests were used to determine if significant differences between weight-at-age of fish from recent year-classes were present. Data were available to test age-1 differences for the 1978 and $1980-82$ yearclasses; age-2 differences for the 1978--82 and 1984 year-classes and age-3 differences for the 1978, 1981 and 1982 year-classes. Comparison estimators were then calculated to determine which year-classes were statistically different for each age group (Hollander and Wolfe, 1973). This test (Miller large sample comparison) is a series of two-sample comparisions that isolate year-class differences and the faster growing cohort. Finally, contrast estimators were obtained for each set of two-sample comparisons (Hollander and Wolfe, 1973), to allow the magnitude of the difference between each two sample pair to be calculated (in this case the difference in weight $(\mathrm{g})$ between each year-class).

\section{Results}

Regressions of survey mean weight-at-age versus stock size suggested that at ages 1-3 a significant negative relationship existed. For ages 4 and 5 , the relationship was non-significant (Table 1).

Results from analysis of the data on commercial mean weight suggested a negative relationship

TABLE 1. Statistics from regressions of mean weights-at-age of Atlantic mackerel versus stock size (1+ numbers) from Virtual Population Analysis for spring bottom trawl surveys (Northeast Fisheries Center, 1976-85, and commercial landings, 1967-85)

\begin{tabular}{|c|c|c|c|c|c|c|c|c|c|c|}
\hline \multirow[b]{2}{*}{ Age } & \multicolumn{5}{|c|}{ Spring surveys } & \multicolumn{5}{|c|}{ Commercial landings } \\
\hline & $\mathrm{n}$ & $r$ & $r^{2}$ & $\mathrm{~F}$ & $\mathrm{p}$ & $n$ & $r$ & $r^{2}$ & $\mathrm{~F}$ & $\mathrm{p}$ \\
\hline 1 & 9 & -0.727 & 0.528 & 7.86 & 0.026 & 19 & -0.417 & 0.174 & 3.58 & 0.076 \\
\hline 2 & 8 & -0.701 & 0.492 & 5.80 & 0.053 & 19 & -0.556 & 0.309 & 7.59 & 0.014 \\
\hline 3 & 8 & -0.676 & 0.456 & 5.04 & 0.066 & 19 & -0.594 & 0.353 & 9.27 & 0.007 \\
\hline 4 & 9 & -0.113 & 0.013 & 0.09 & 0.772 & 19 & -0.501 & 0.251 & 5.71 & 0.029 \\
\hline 5 & 10 & 0.351 & 0.124 & 1.13 & 0.319 & 19 & -0.431 & 0.186 & 3.89 & 0.065 \\
\hline 6 & & & & & & 19 & -0.399 & 0.159 & 3.22 & 0.091 \\
\hline 7 & & & & & & 19 & -0.361 & 0.130 & 2.56 & 0.130 \\
\hline 8 & & & & & & 19 & -0.405 & 0.164 & 3.33 & 0.086 \\
\hline 9 & & & & & & 19 & -0.410 & 0.168 & 3.44 & 0.081 \\
\hline
\end{tabular}


between weight and stock size for ages 1-9 (Table 1). The results were significant at $P=0.05$ for ages $2-4$ and nearly so for ages 1 and 5 (Table 1). Beyond age 5, the relationships also were not significant at the 0.05 level, but they were, with the exception of age 7 , significant at the 0.1 level.

When mean weights at age 1 and 2 from individually weighed fish were used in regressions with yearclass size-at-age, correlation coefficients were relatively high at $r=-0.77$ and -0.75 respectively. The relationships were not significant at $P=0.05$ for age 1 and $2(P=0.226, n=4$ and $P=0.082, n=6$ respectively $)$, but this was not surprising since there were only a few degrees of freedom. Analysis of the age- 3 data was not attempted because only three data points were available.

Mean weight-at-age was disparate for the various year-classes (Fig. 3). Growth analyses based on individual weights of fish from different year-classes (1978-82, 1984) indicated very different annual growth patterns in the stock from 1979 to 1985. The KruskalWallis tests showed that highly significant differences existed between age 1-3 fish for all the year-classes investigated (Tables 2, 3 and 4). Multiple comparison estimators for age-1 fish showed that the 1980 year-

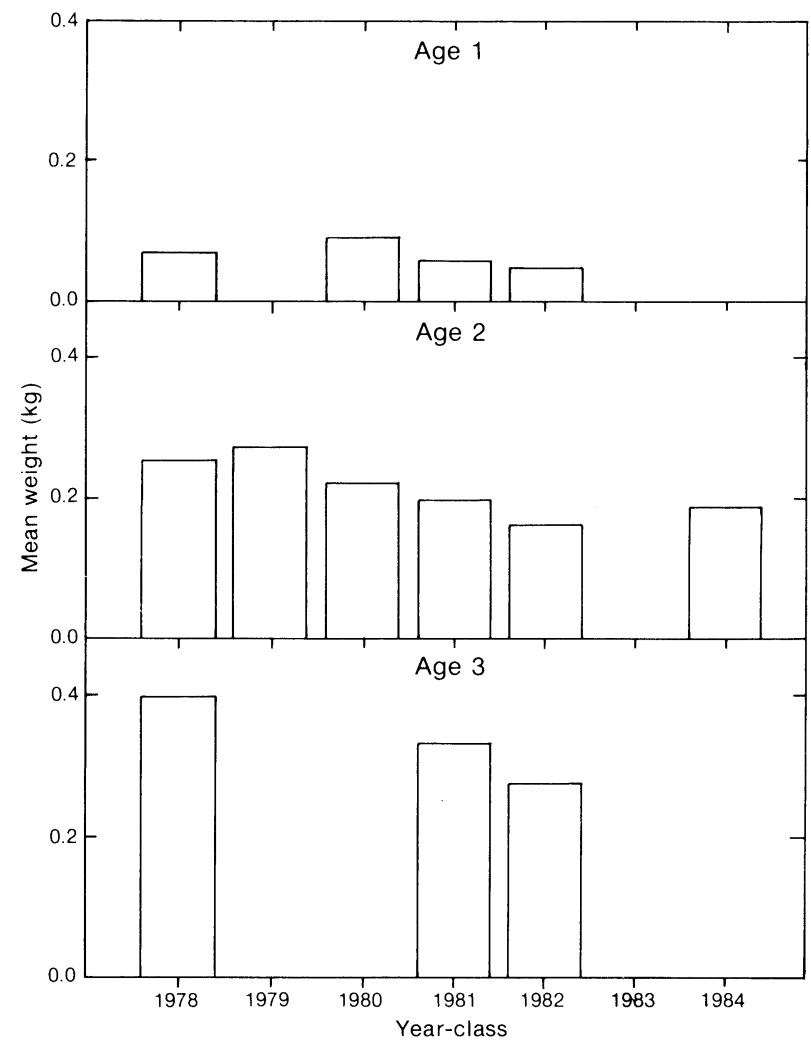

Fig. 3. Mean weight-by-age group (kg) ages 1-3 for Atlantic mackerel from the 1978-82 and 1984 year-classes. class attained the largest size of all the cohorts sampled. Both 1978 and 1980 year-classes grew faster than the 1981 and 1982 cohorts (Table 2). Contrast estimators for this age group showed that, on average, the 1980 cohort was almost 37 and $50 \mathrm{~g}$ larger than the 1981 and 1982 cohorts respectively (Fig. 4).

Several more year-classes were available for analysis of relationships at age 2. The 1978-80 year-classes all grew faster in the second year of life than the 1981, 1982 and 1984 cohorts (Table 3 ). The results indicated that the 1979 year-class was about 81,110 , and $91 \mathrm{~g}$

TABLE 2. Results of non-parametric analysis of variance ${ }^{a}$ (KruskalWallis tests) for age 1 fish from the 1978 and 1980-82 yearclasses of Atlantic mackerel.

\begin{tabular}{ccccc}
\hline \hline $\begin{array}{l}\text { Year- } \\
\text { class }\end{array}$ & $\mathrm{n}$ & $\begin{array}{c}\text { Rank } \\
\text { sum }\end{array}$ & $\begin{array}{c}\text { Mean } \\
\text { score }\end{array}$ & $\begin{array}{c}\text { Chi } \\
\text { square }\end{array}$ \\
\hline 78 & 36 & 2984 & 82.88 & \\
80 & 36 & 3609 & 100.24 & \\
81 & 36 & 2291 & 63.62 & \\
82 & 36 & 1558 & 43.26 & \\
& & & & $37.47^{\mathrm{b}}$
\end{tabular}

a Results of multiple comparison tests were that none of the treatment comparisons were equal, $p \leqslant 0.05$, and the weight of the 1980 cohort $>78>81>82$

${ }^{b} \mathrm{p} \leqslant 0.01$

TABLE 3. Results of non-parametric analysis of variance ${ }^{a}$ (KruskalWallis tests) for age 2 fish from the 1978-82, and 1984 yearclasses of Atlantic mackerel.

\begin{tabular}{lcccc}
\hline \hline $\begin{array}{l}\text { Year- } \\
\text { class }\end{array}$ & $\mathrm{n}$ & $\begin{array}{c}\text { Rank } \\
\text { sum }\end{array}$ & $\begin{array}{l}\text { Mean } \\
\text { score }\end{array}$ & $\begin{array}{c}\text { Chi } \\
\text { square }\end{array}$ \\
\hline 78 & 30 & 3884 & 129.47 & \\
79 & 30 & 4373 & 145.75 & \\
80 & 30 & 3021 & 100.68 & \\
81 & 30 & 1896 & 63.18 & \\
82 & 30 & 1335 & 44.50 & \\
84 & 30 & 1782 & 59.42 & \\
& & & & $93.97^{\text {b }}$ \\
\hline
\end{tabular}

a Results of multiple comparison texts were that none of the treatment comparisons were equal, $p \leqslant 0.05$, and the weight of the 1979 cohort $>78>80>81>84>82$.

${ }^{b} \mathrm{p} \leqslant 0.01$

TABLE 4. Results of non-parametric analysis of variance ${ }^{a}$ (Kruskal- $^{-}$ Wallis tests) for age 3 fish from the 1978 and 1981-82 yearclasses of Atlantic mackerel.

\begin{tabular}{lcccc}
\hline $\begin{array}{l}\text { Year- } \\
\text { class }\end{array}$ & $\mathrm{n}$ & $\begin{array}{c}\text { Rank } \\
\text { sum }\end{array}$ & $\begin{array}{l}\text { Mean } \\
\text { score }\end{array}$ & $\begin{array}{c}\text { Chi } \\
\text { square }\end{array}$ \\
\hline 78 & 50 & 5559 & 111.18 & \\
81 & 50 & 3679 & 73.58 & \\
82 & 50 & 2087 & 41.74 & \\
& & & & $64.02^{\text {b }}$
\end{tabular}

${ }^{a}$ Results of multiple comparison tests were that none of the treatment comparisons were equal, $p \leqslant 0.05$, and the weight of the 1978 cohort $>81>82$.

b $\mathrm{p} \leqslant 0.01$ 


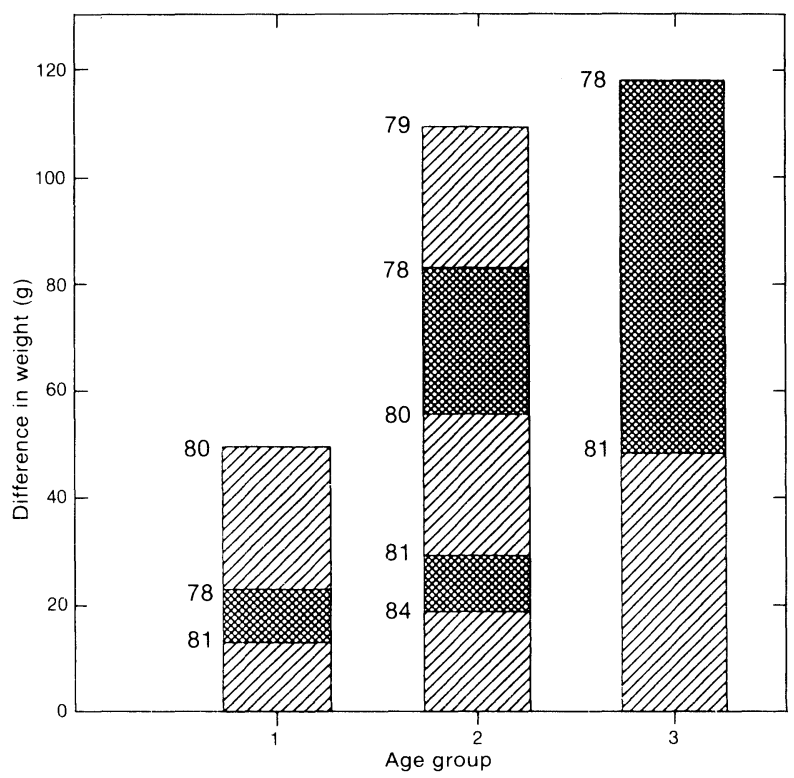

Fig. 4. Differences in weight ( $\mathrm{g}$ ) from Hodges-Lehman contrast estimates between the 1978-82 and 1984 year-classes of Atlantic mackerel. The 1982 year-class is the slowest growing cohort and is used as the standard year of comparison for age groups 1-3. The bars are cumulative for each age group: for example for age-3, the 1981 cohort is roughly $50 \mathrm{~g}$ larger than the 1982 cohort, and the 1978 cohort is roughly $70 \mathrm{~g}$ larger than the 1981 cohort and $120 \mathrm{~g}$ larger than the 1982 cohort

larger than the 1981, 1982 and 1984 cohorts respectively (Fig. 4). In all cases, the 1982 year-class showed the slowest growth of any cohort, followed by the 1984 and 1981 cohorts. The 1984 year-class, although smaller in size than the 1981 year-class, appeared to have grown more slowly (Fig. 4; age group 2).

Information for the analysis of growth patterns for age-3 fish were only available for the 1978, 1981, and 1982 year-classes because other cohorts waie not adequately represented in the scientific survey and Polish commercial fishery catches. The three year-classes were significantly different in average weight-at-age (Table 4). Comparison estimators showed that the 1978 year-class was significantly larger than the 1981 and 1982 year-classes, and that the 1981 year-class fish were larger at age- 3 than the 1982 year-class (Table 4). Contrast estimators further indicated that the 1978 year-class averaged 70 and $119 \mathrm{~g}$ larger than the 1981 and 1982 year-classes respectively (Fig. 4).

\section{Discussion}

The possible density-dependent link to growth in the Atlantic mackerel stock found along the coast of eastern Canada and the USA suggested in this study is in agreement with some previous reports (McKay, 1979; Lett, 1980). Significant relationships between both survey mean weights at ages 1-3 and stock size and commercial mean weights at ages 2-4 and stock size were obtained. Significant results $(P=<0.1)$ for age 1 and ages 5-6, and 8-9 were also obtained for the commercial data, probably because older age groups were better represented in the commercial samples. It appears that lengths-at-age vary with stock size and therefore, fish weights change because fish are smaller in size.

Negative relationships between cohort mean weights-at-age and year-class size at ages 1 and 2 were also obtained. Because the age-2 relationship was based on a slightly larger sample size $(n=6)$, and because nearly significant results were obtained, the suggestion that a significant negative relation between year-class size and weight would result if several more cohorts were available for the analysis is probably justified.

The magnitude of the differences between cohort weights from the late-1970s and early-1980s was quantified in these analyses. The 1982 year-class was the largest on record (1962-86) and its growth pattern the slowest. Survey and catch data suggested that the 1981 and 1984 year-classes were at least moderate in size; growth analysis in this study showed that the 1984 year-class grew more slowly than the 1981 year-class. This may be due to a further slowing of growth as stock biomass has continued to accumulate (Fig. 2). More recent research vessel age samples show that there is considerable overlap in age-at-length for the 1981-85 year-classes (Fig. 5). Length frequencies from Polish commercial fishing operations suggested that the pattern of separate and distinct growth for different cohorts that was apparent in 1983 has been repiaced by a pattern of slower growth and overlapping age groups in 1986 (Fig. 6).

Results from the regression analyses suggested that both year-class size and adult size may be important factors in regulating growth in this stock of Atlantic mackerel. Year-class size may influence the initial pattern of growth during a cohort's first several years. This supposition is consistent with life history information that indicates that juvenile fish (age 0-1) live further inshore than the adult stock (Sette, 1950). A large yearclass would affect inshore food resources heavily, whereas a smaller cohort would have less influence; weight-at-age would be a function of individual annual food ration.

Adult stock size probably plays an important role in regulating growth after a year-class recruits to the adult portion of the population. When the juveniles join the offshore pool of adult fish, they all exploit common food resources and should share common growth responses. 


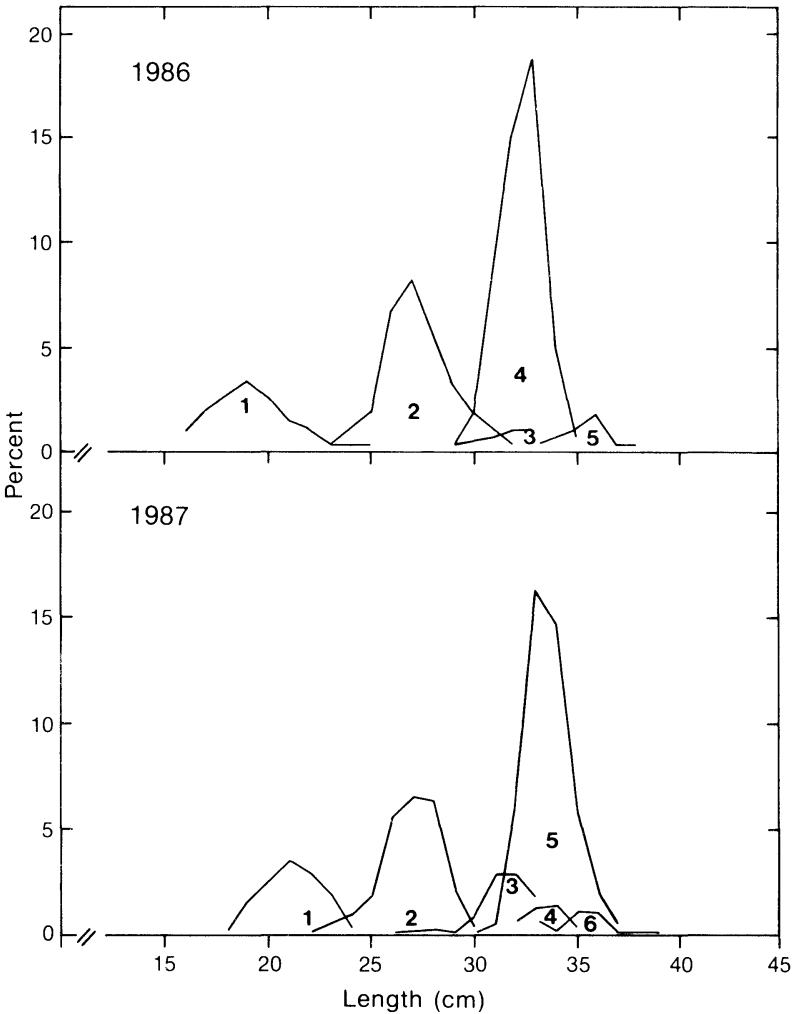

Fig. 5. Length frequencies of Atlantic mackerel by age group for 1986-87 from spring groundfish surveys conducted by the Northeast Fisheries Center.

These life history characteristics suggest that for the purposes of modelling and assessment, a simple two stage growth model that relates a year-class size and adult stock size to growth increments for a yearclass might be appropriate. Because juvenile fish maintain a distribution separate from the adult stock (Sette, 1950), a simple linear relationship between age-1 growth and corresponding age-1 year-class size could be used to predict weight-at-age at age-1. Thus

$$
W t(1)=a-b(N 1),
$$

where $\mathrm{Wt}_{\mathrm{t}}(1)=$ average weight $(\mathrm{g})$ at age-1, N1 = yearclass size at age -1 (numbers), and $a$ and $b$ are parameters specific to age-1.

Adult growth could be determined by linear relationships between adult stock size and growth-at-age. Thus,

$$
W t(i)=W t(i-1)+G(i),
$$

where $W t(i)=$ average weight-at-age $i, G(i)=$ annual age specific growth increment $(\mathrm{g})$, and $i=2,3, \ldots . \mathrm{n}$.

Also

$$
G(i)=a(i)-b(i) S S,
$$

where SS = total adult stock size (numbers) and $a$ and $b$ are age-specific parameters.

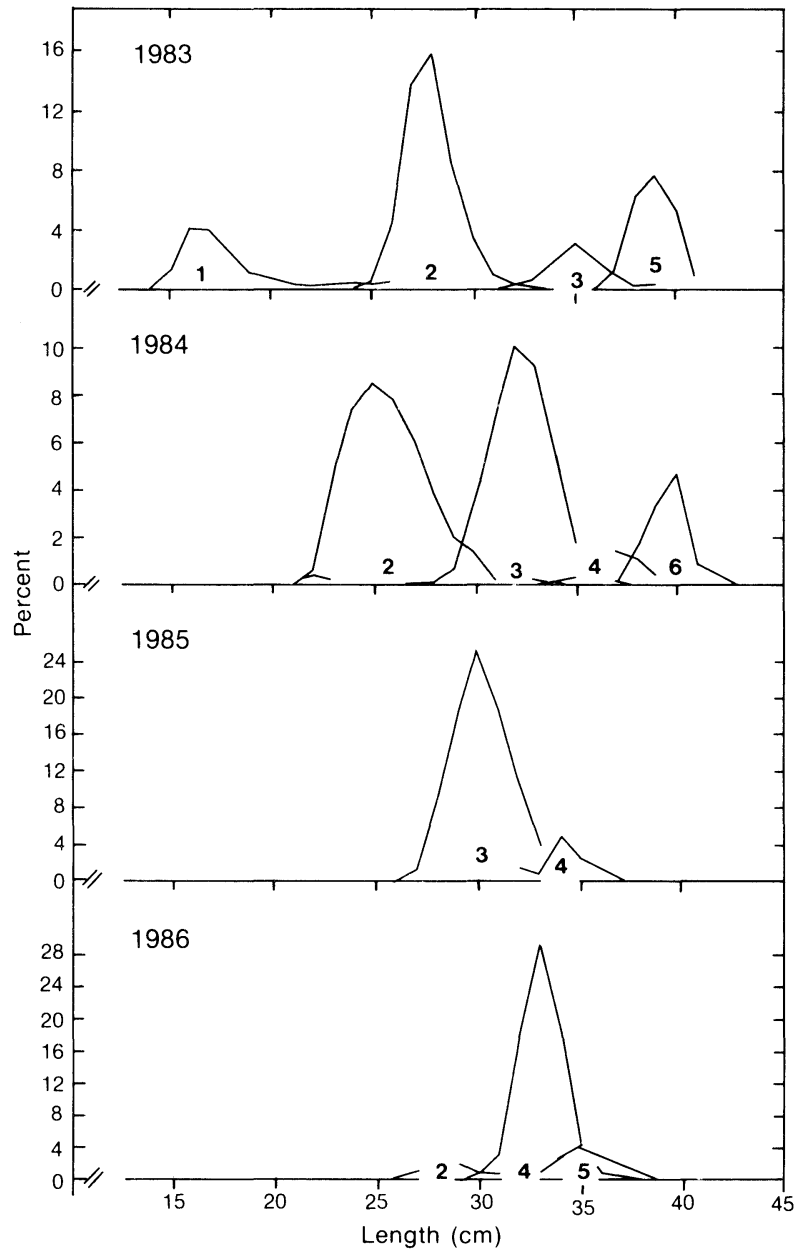

Fig. 6. Length frequencies of Atlantic mackerel by age group for 1983-86 from Polish comercial catches.

Weight-at-age would be the result of growth in the first year plus subsequent increments through the adults growth phase; thus age-1 growth would partially determine the weight of a fish throughout its lifetime. If the stock was reduced in any given year, the cohort could eventually recover and grow faster. This conceptual model could be parameterized if data on age-1 growth and year-class size and age 2, 3 ...., n growth increments and total stock were available. At present, there is not enough detailed growth information on the Northwest Atlantic mackerel stock to fit the model.

Because fishery managers frequently depend on forecasts from stock assessments to predict future yields from fishery resources, reliable and accurate models of key population processes are essential. Estimates of future yields require predictions of incoming recruitment and the recent pattern of growth in the stock. Often the weight-at-age values used in predictions are from previous time periods, perhaps several years old. Although they may be valid indicators of recent growth trends in a stock, they may be only useful for a short-term forecast. If fishery patterns or recruit- 
ment are changing rapidly, mean weights from previous years will not be useful even in the short-term and may be wholly inaccurate for a long-term projection. For fish stocks with strong-density dependent growth responses, a model such as the one proposed, could be useful for providing an estimate of yield.

\section{Acknowledgements}

I thank the personnel from the Northeast Fisheries Center who have tirelessly collected data on research vessel surveys over the last 25 years. I am also grateful to the foreign fishery observers and scientists who collected the data from Polish commercial operations. Special thanks to L. M. Dery who aged all the fish used in this study.

\section{References}

ANDERSON, E. D., and A. J. PACIORKOWSKI. 1980. A review of the Northwest Atlantic mackerel fishery. ICES Rapp. Proc.-Verb., 177: 175-211.

AZAROVITZ, T. R. 1981. A brief historical review of the Woods Hole laboratory trawl survey time series. Can. Spec. Pub. Fish. Aquat. Sci., 58: 62-67.

BACKIEL, T., and E. D. LeCREN. 1967. Some density relationships for fish population parameters (p. 261-294). S. D. Gerking (ed.). John Wiley and Sons, New York.

BORGENSEN, D. P. 1966. Trout lake management ( $p$. (168-178). In: Inland fisheries management. A. Calhoun (ed.) The State of California. Department of Fish and Game.

CLARK, S. H., W. J. OVERHOLTZ, and R. C. HENNEMUTH. 1982. Review and assessment of the Georges Bank and Gulf of Maine haddock fishery. J. Northw. Atl. Fish. Sci., 3: 1-27.

GROSSLEIN, M. D. 1969. Groundfish survey program of BCF, Woods Hole. Comm. Fish. Rev. 31(8-9): 22-35.

HOLLANDER, M., and D. A. WOLFE. 1973. Nonparametric statistical methods. John Wiley and Sons, New York.

HOY, D. L., and G. M. CLARK. MS 1967. Atlantic mackerel fishery, 1804-1965. US Dept. Interior, Fish. Leafl., 603, $9 \mathrm{p}$.

IVLEV, V. S. 1961. Experimental ecology of the feeding of fishes. Yale University Press, New Haven.

JENSEN, A. C. MS 1967. A brief history of the New England offshore fisheries. US Dept. Interior, Fish. Leafl., 594, 14 p.

LETT, P. F. 1980. A comparative study of the recruitment mechanisms of cod and mackerel, their interaction, and its implication for dual stock assessment. Can. Tech. Rep. Fish. Aquat. Sci., 988: 45 p.

McKAY, K. T. 1979. Synopsis of biological data of the northern population of Atlantic mackerel (Scomber scombrus). Tech. Rep. Can. Fish. Mar. Ser., 885, 26 p.

MOREAU, J. 1987. Mathematical and biological expression of growth in fishes: Recent trends and further developments. (p. 81-113). In: Age and growth of fish. R. C. Summerfelt and G. E. Hall (eds.). lowa State University Press, Ames.

OVERHOLTZ, W. J., S. A. MURAWSKI, W. L. MICHAELS and L. M. DERY. MS 1988. The effects of density dependent population mechanism on assessment advice for the Northwest Atlantic mackerel stock. NOAA Tech. Mem., NMFS-F/NEC-62, $49 p$

ROSS, M. R., and F. P. ALMEIDA. 1986. Density-dependent growth of silver hakes. Trans. Amer. Fish. Soc., 115: 548-554

SETTE, O. E. 1950. Biology of the Atlantic mackerel (Scomber scombrus) of North America. Part 2. Migrations and habits. Fish. Bull. US, 51: 251-358.

SETTE, O. E., and A. W. H. NEEDLER. 1934. Statistics of the mackerel fishery off the coast of North America. Invest. Rep., US Dept. Commer., 19, 48 p.

TEMPLEMAN, W., and C. A. BISHOP. 1979. Sexual maturity and spawning in haddock Melanogrammus aeglefinus, of St. Pierre Bank. ICNAF Res. Bull., 14: 77-83.

TYLER, A. V., and R. S. DUNN. 1976. Ration, growth and measures of somatic and organ condition in relation to mean frequency in winter flounder, Pseudopleuronectes americanus, with hypotheses regarding population homeostasis. J. Fish. Res. Board Can., 33: 63-75.

WEATHERLY, A. H., and H. S. GILL. 1987. The biology of fish growth. Academic Press, London. 
